\title{
Domains of the adenovirus E1A protein required for oncogenic activity are also required for dissociation of $\mathrm{E} 2 \mathrm{~F}$ transcription factor complexes
}

\author{
Pradip Raychaudhuri, ${ }^{1}$ Srilata Bagchi, ${ }^{2}$ Stephen H. Devoto, Virginia B. Kraus, Elizabeth Moran, ${ }^{3}$ \\ and Joseph R. Nevins
}

Howard Hughes Medical Institute, Section of Genetics, Department of Microbiology and Immunology, Duke University Medical Center, Durham, North Carolina 27710 USA; ${ }^{3}$ Cold Spring Harbor Laboratory, Cold Spring Harbor,

New York 11724 USA

\begin{abstract}
Recent experiments have shown that the cellular E2F transcription factor is found in complexes with cellular proteins and that one such complex contains the cyclin-A protein. Isolation of a cellular activity, which we term E2F-BF, can reconstitute the E2F-cyclin-A complex and has permitted a more detailed analysis of the mechanism of E1A dissociation. Through the analysis of a series of E1A mutants, we find that sequences in conserved region 1 (CR1) and conserved region 2 (CR2) are important for dissociation of the E2F complex, whereas amino-terminal sequences are not required. In contrast to the requirements for dissociation, only the CR1 sequences are required to block formation of the complex if $E 1 A$ is added when the components are combined. We have also identified an activity, termed E2F-I, that inhibits E2F binding to DNA, again apparently through the formation of a complex with E2F. This inhibitory activity is also blocked by E1A, dependent on the same elements of the E1A protein that disrupt the interaction with E2F-BF. Because the E1A sequences that are important for releasing E2F from these interactions are also sequences necessary for oncogenesis, we suggest that this activity may be a critical component of the transforming activity of E1A.
\end{abstract}

[Key Words: E2F-BF; Cyclin A adenovirus E1A protein; oncogenic activity; E2F transcription factor]

Received January 16, 1991; revised version accepted May 9, 1991.

The control of transcription initiation of RNA polymerase II-transcribed genes is a complex process involving the interaction of multiple DNA-binding proteins with specific regulatory sequences within promoter and enhancer elements (for review, see Mitchell and Tjian 1989|. Moreover, it is now clear that the proteins that bind to these elements do not always do so as simple monomers; rather, multicomponent complexes are often the active form. For instance, during a herpes simplex virus infection, the virus-encoded VP16 protein associates with the cellular Oct-1 transcription factor to direct transcription from various immediate early herpesvirus promoters (McKnight et al. 1987; Gerster and Roeder 1988; O'Hare and Coding 1988; Preston et al. 1988). As another example, the active form of the serum response factor (SRF), which mediates a stimulation of fos transcription following serum stimulation, appears to be a multicomponent complex (Shaw et al. 1989). Finally, recent studies have suggested the involvement of acces-

Present addresses: University of Illinois, Chicago, 'Department of Biochemistry, ${ }^{2}$ College of Dentistry, Chicago, Illinois 60612 USA. sory factors that may bridge the interactions between various upstream binding factors as well as with basal factors such as TFIID (Pugh and Tjian 1990).

A series of recent experiments have demonstrated that a product of the adenovirus early E4 transcription unit forms a complex with the cellular E2F transcription factor to allow cooperative binding at the E2 promoter (Hardy et al. 1989; Huang and Hearing 1989; Reichel et al. 1989; Marton et al. 1990; Neill et al. 1990; Raychaudhuri et al. 1990). The binding of E2F/E4 complexes at adjacent promoter sites generates a very stable DNA complex and ultimately a stimulation of E2 transcription. The observation that adenovirus E4 protein can interact with $\mathrm{E} 2 \mathrm{~F}$ to alter its function suggests that there may be cellular proteins that also interact with E2F. Indeed, recent experiments have shown this to be the case (Bagchi et al. 1990). Although the precise function of E2F complexes within the cell is not clear, they are significant for a viral infection in that they prevent interaction with the E4 protein. Perhaps the most intriguing aspect of these recent studies is the finding that the adenovirus E1A protein can dissociate E2F from these cellular complexes (Bagchi et al. 1990). This dissociation then allows 
the E4 protein to interact with E2F and form the stable promoter complex.

In the absence of a viral infection, we believe that the E2F interactions may influence the activity of E2F in relation to cell proliferation controls. E2F-binding sites can be found in regulatory regions of several genes that respond to serum addition (Mudryj et al. 1990), and mutagenesis has shown the importance of the E2F sites in the c-myc promoter (Lipp et al. 1987; Hiebert et al. 1989; Mudryj et al. 1990), as well as the dihydrofolate reductase (DHFR) promoter (Blake and Azizkhan 1989). E2Fbinding activity changes dramatically following serum stimulation. There is an initial rise in the overall level of E2F as cells progress from a quiescent state to a growing state (Mudryj et al. 1990). As the cell proceeds through $G_{1}$ and into $S$ phase, there are changes in the interactions involving E2F, as judged by gel mobility-shift assays (Mudryj et al. 1991). Clearly, an alteration in the normal interaction involving this cellular transcription factor could alter normal cellular gene expression. This becomes a particularly relevant issue considering that the initial assays indicated that the 243-amino-acid E1A product, which is sufficient for E1A-dependent cell transformation, was capable of this activity. We have now explored this question further by analyzing a series of E1A mutants to precisely define the essential sequences. The results define a requirement for separate regions of the protein in distinct events and suggest a correlation between this activity and E1A-mediated transformation.

\section{Results}

E1A protein sequences within conserved regions 1 and 2 are required for dissociation of the E2F complex

Our recent experiments have demonstrated that the activity of the adenovirus E1A protein that mediates a dissociation of complexes containing the E2F transcription factor is independent of ElA conserved region 3 (CR3) but dependent on conserved region 2 (CR2) (Bagchi et al. 1990). To define more precisely the ElA protein sequences necessary for the activity and, therefore, to provide information as to the relationship with other known activities of the ElA protein, we have made use of a collection of mutants that target various portions of the 243-amino-acid protein product of the $12 \mathrm{~S} \mathrm{E1A}$ mRNA. As depicted in Figure 1, these mutants alter the amino terminus of the protein, conserved region 1 (CRl), CR2, and the sequence between the two conserved regions. Each mutant was constructed in the form of a cDNA in a pGEM vector that could be transcribed in vitro by SP6 RNA polymerase. The RNA products were then translated in a reticulocyte lysate to produce the corresponding proteins. Each reticulocyte lysate was then assayed for E2F-dissociating activity by incubation with an L-cell whole-cell extract, as described in previous assays (Bagchi et al. 1990).

As we have reported previously (Bagchi et al. 1990) and as shown in Figure 2, lane 3, the wild-type 12S E1A prod-

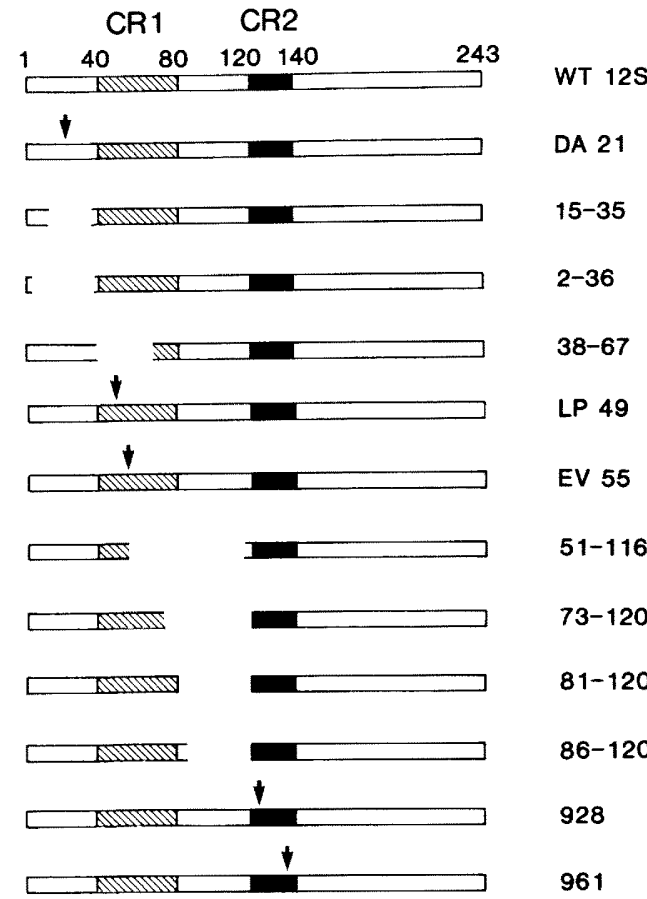

Figure 1. Structure of ElA mutants. The wild-type 243-aminoacid product of the 12S ElA RNA. The two regions that exhibit sequence conservation among various adenovirus serotypes (Kimelman et al. 1985) are indicated. Point mutations are indicated by arrows; the name of the mutant indicates the amino acid position, with the exception of 928 and 961, which refer to nucleotide positions. Deletions are depicted by gaps; the positions are indicated in the mutant identification.

uct was able to dissociate the E2F complex $\left(E 2 F_{c}\right)$, as indicated by the disappearance of the slowly migrating gel complex $\left(E 2 F_{L}\right)$ and the appearance of the faster mobility complex characteristic of the interaction of a single E2F molecule with the DNA (E2F). In contrast, addition of a reticulocyte lysate programmed with a control brome mosaic virus (BMV) RNA had no effect on $E_{2} F_{c}$ (lane 2). The two E1A amino-terminal mutants were also capable of dissociating the complex (lanes 4 and 5), as were two point mutants in CR 1 (lanes 8 and 9). Furthermore, two deletion mutants that removed sequence between CR1 and CR2 (lanes 10 and 11) also showed full wild-type activity. In contrast, the two deletion mutants within CR1 (lanes 6 and 7), as well as the two point mutants within CR2 (lanes 12 and 13), were inactive in dissociating $\mathrm{E}_{2} \mathrm{~F}_{\mathrm{c}}$. An analysis of the in vitro translation products demonstrated that there was roughly equal synthesis of each of the mutant proteins (data not shown). We thus conclude that sequences within both CR1 and CR2 are required for the E2F-dissociating activity, whereas sequences at the amino terminus of the protein, as well as sequences between CR1 and CR2, are not required.

\section{$C R 1$ and $C R 2$ are required for trans-activation}

Our previous experiments have shown that a plasmid expressing the $12 \mathrm{~S}$ E1A product can trans-activate an 


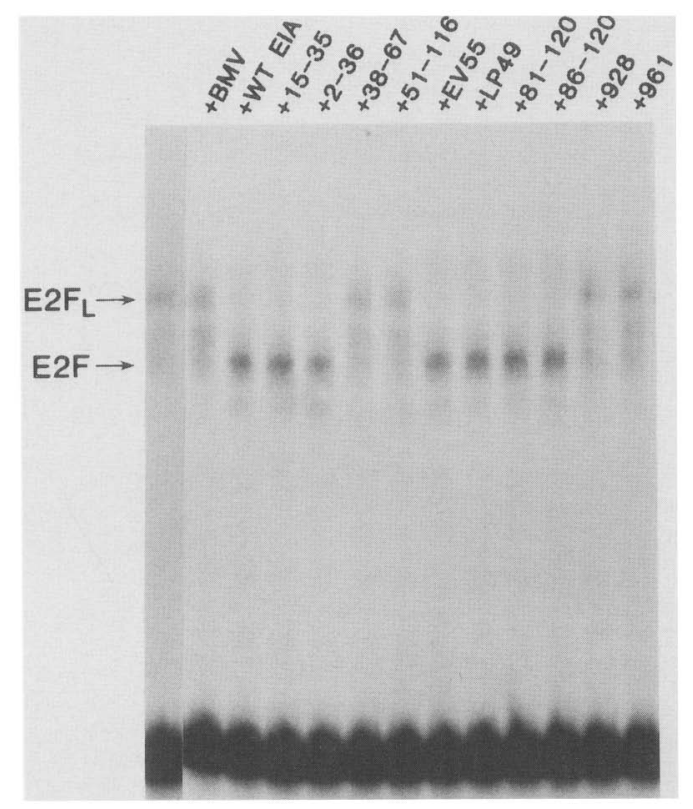

Figure 2. Dissociation of $E 2 F_{c}$ by wild type and mutants of E1A. E2F-binding activity was measured in the L-cell whole-cell extract (lane 1) or after the addition of $1 \mu \mathrm{l}$ of a $1: 5$ dilution of reticulocyte lysate programmed with $12 \mathrm{~S}$ E1A mRNA (WT ElA) or the mRNAs derived from the mutants as described in Fig. 1. Reticulocyte lysates programmed with BMV RNA were used as control.

E2F-dependent promoter but that this activity is dependent on the cell line (Bagchi et al. 1990). That is, there was little if any trans-activation in HeLa cells, whereas the trans-activation in L cells was only slightly less efficient than that of the $13 \mathrm{~S}$ ElA product. This result correlates with the presence or absence of E2F in complexes, thus providing an explanation for variable results of many past experiments measuring E1A trans-activation because most of these experiments utilized HeLa cells, cells in which E2F is largely in a free, uncomplexed state. These results would also suggest that complexed E2F is inhibitory for E2 transcription.

Although these experiments demonstrated a requirement for CR2 sequence for this activity, because the point mutation 928 was defective, they did not define precisely the E1A sequence requirements. Because the results of Figure 2 clearly demonstrate a role for CRl in addition to CR2 in the dissociation of E2F complexes, we have now assayed several of these additional mutants for trans-activating function. L cells were transfected with the pA10CAT-E2F plasmid alone or in combination with wild-type $12 \mathrm{~S}$ ElA or the mutants indicated. Extracts were prepared after $48 \mathrm{hr}$ and assayed for chloramphenicol acetyltransferase (CAT) activity (Fig. 3). Clearly, both of the domain 1 mutants were completely defective for trans-activation. The domain 2 mutant 961 was also impaired, although reproducibly not as much as the domain 1 mutants, a result observed previously for one other CR2 mutant, 928 (Bagchi et al. 1990). In con- trast, an amino-terminal mutant $(\Delta 15-35)$, as well as a mutant that deleted sequence between domains 1 and 2 ( $\Delta 86-120)$, had no effect on the trans-activating function. We therefore conclude that both E1A domains 1 and 2 are required for dissociation of the E2F complexes, as well as for full trans-activation of a promoter dependent on E2F for activity. In the absence of CR2, some transactivation persists, although it is severely reduced.

\section{Isolation of an E2F-binding factor that reconstitutes a} cyclin A-containing E2F

Although the results presented thus far provide insight into the E1A requirements for dissociation of $\mathrm{E} 2 \mathrm{~F}_{\mathrm{c}}$ a better understanding of the mechanism of E1A action clearly requires the ability to manipulate the system using purified components. We have thus sought to isolate the factor that forms a complex with E2F so as to be able to reconstitute the association of the components in vitro.

Because virtually all of the E2F detected in extracts of mouse $L$ cells appeared to be complexed to a cellular factor(s) (Bagchi et al. 1990), we reasoned that there might be an excess of the factor that forms the complex with E2F in these cells. Indeed, fractionation of an L-cell extract by heparin-agarose chromatography revealed an activity in a $0.25 \mathrm{M} \mathrm{KCl}$ eluate that could interact with E2F to generate a complex that migrated at a position typical of the complex detected in crude extracts (Fig. 4A). The $0.25 \mathrm{M}$ fraction possessed no E2F-binding activity of its own, and the endogenous E2F was found to elute in the $0.75 \mathrm{M} \mathrm{KCl}$ wash (data not shown). It thus appears that an E2F-binding factor (E2F-BF) can be detected in the $0.25 \mathrm{M}$ eluate. We have further purified the E2F-BF by chromatography of the heparin-agarose $0.25 \mathrm{M}$

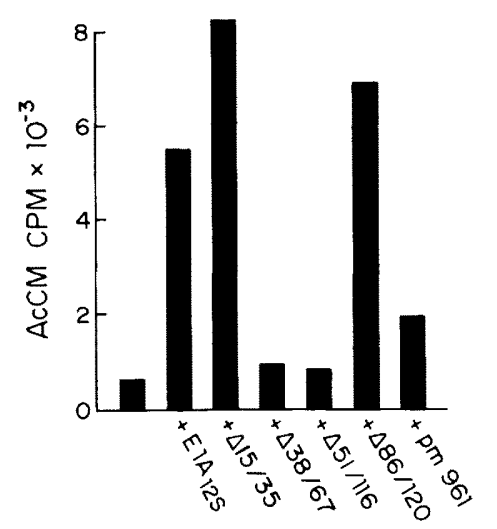

Figure 3. Trans-activation by wild-type E1A and E1 A mutants. The pA10CAT-E2F plasmid, which exhibits an E2F-dependent response to ElA, was used as a reporter gene for measuring E2F-dependent trans-activation. L cells were transfected with the PA10CAT-E2F plasmid, either alone or together with the wild-type $12 \mathrm{~S}$ E1A-expressing plasmid, or the $12 \mathrm{~S}$ E1A plasmids bearing the various mutations. Extracts were prepared and CAT activity was measured as described in Materials and methods. 

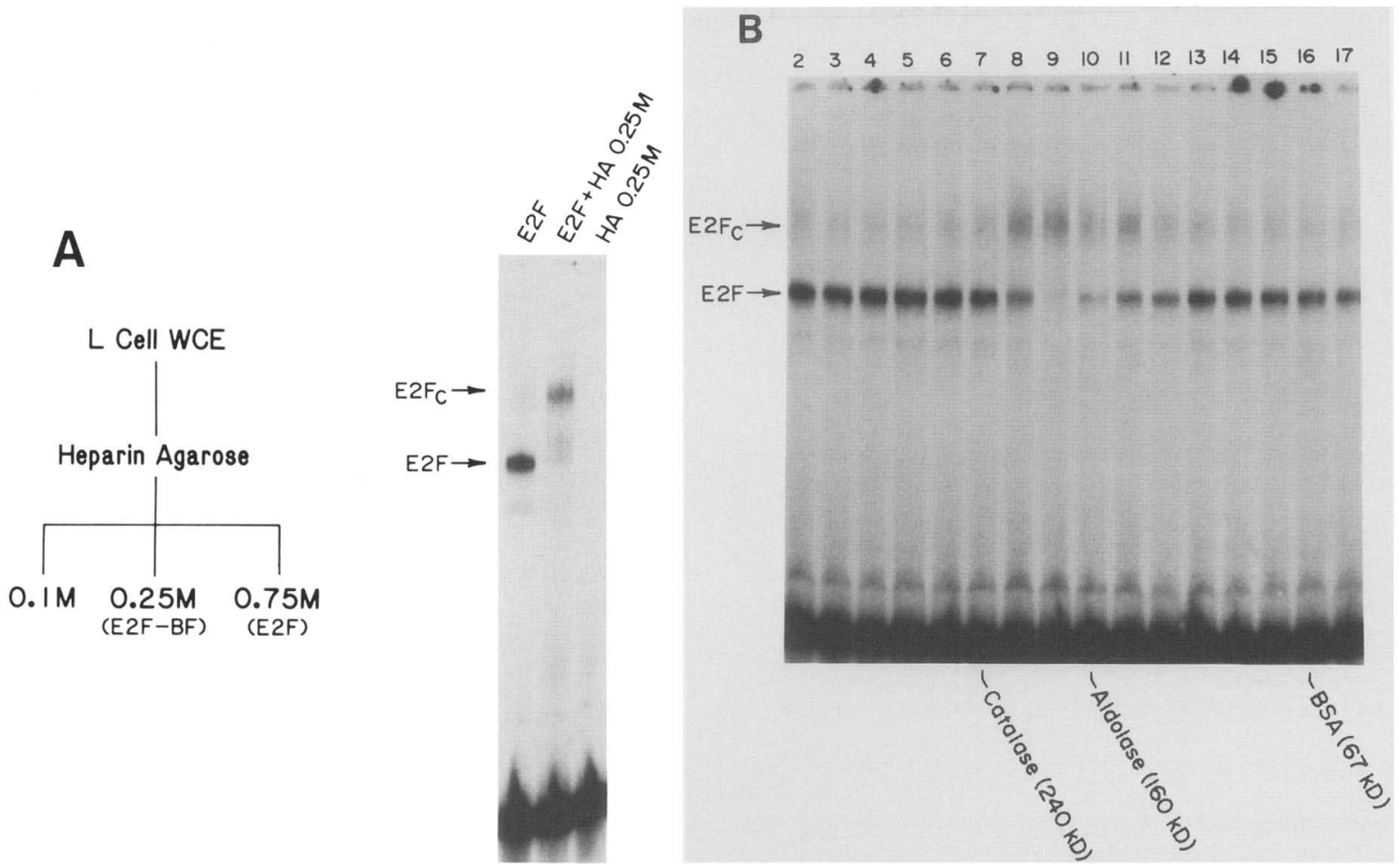

Figure 4. Identification of E2F-BF in L-cell extracts. $(A)$ L-cell extracts were fractionated on a heparin-agarose column as described in Materials and methods. A $0.25 \mathrm{M}$ eluate $(2 \mu \mathrm{g})$ from the column (HA $0.25 \mathrm{M})$, which is free of any E2F-binding activity, was assayed alone (lane 3) or after incubation with a sample of E2F (lane 2). Assay of the E2F sample alone is shown in lane $1 .(B)$ Glycerol gradient sedimentation. Peak fractions from hydroxyapatite chromatography of the E2F-BF preparation (see Materials and methods) were concentrated and analyzed by sedimentation in a $12-35 \%$ glycerol gradient as described. Individual fractions were assayed for E2F-BF activity. A gradient containing the indicated marker proteins was run in parallel.

fraction on DEAE-Sepharose followed by hydroxyapatite. Sedimentation of the hydroxyapatite-purified E2F$\mathrm{BF}$ in a glycerol gradient yielded a single peak of activity with an estimated molecular mass of $\sim 180 \mathrm{kD}$ (Fig. $4 \mathrm{~B}$ ). Whether this represents a single polypeptide or multiple components is not yet clear.

Our recent experiments have identified the cyclin-A protein as a component of an E2F complex found during $S$ phase in $3 T 3$ cells, as well as in asynchronously growing cells (Mudryj et al. 1991). As shown in Figure 5, E2F reconstituted with the partially purified E2F-BF does contain the cyclin-A polypeptide. Addition of cyclin-A antiserum to the mixture abolished $\mathrm{E}_{\mathrm{F}} \mathrm{F}_{\mathrm{c}}$ but had no effect on the free E2F. Moreover, addition of a cyclin Bspecific antiserum did not alter $\mathrm{E} 2 \mathrm{~F}_{\mathrm{c}}$. Although we do not know as yet whether the source of the cyclin-A protein derives from E2F-BF preparation or the extract that provides $\mathrm{E} 2 \mathrm{~F}$, it does appear from this analysis that $\mathrm{E}_{2} \mathrm{~F}_{\mathrm{c}}$ reconstituted with the $\mathrm{E} 2 \mathrm{~F}-\mathrm{BF}$ is authentic, as judged by the gel mobility as well as the involvement of cyclin A.

\section{Reconstitution of $E 2 F_{c}$ with E2F-BF reveals different roles for E1A CR1 and CR2}

The availability of a partially purified factor that can form a complex with the E2F transcription factor has allowed us to further investigate the properties of this interaction and the mechanism by which ElA is able to dissociate the complex. As shown in Figure 6A, the complex generated with E2F and E2F-BF was sensitive to dissociation by the wild-type 243 -amino-acid 12 S E1A product (lane 5). Moreover, utilization of the various E1A mutants again revealed a requirement for CR1 and CR2 for the dissociation of the complex-results identical to those seen for the dissociation of $\mathrm{E}_{2} \mathrm{~F}_{\mathrm{c}}$ in $\mathrm{L}$ whole-cell extracts. We therefore conclude that the reconstituted system exhibits the same requirements for E1A, thus indicating the authenticity of the assay system and the likelihood that the purified E2F-BF is that which is found in the complex with E2F in the crude lysates.

The availability of E2F-BF allows the effects of E1A to be assayed in a somewhat different manner. As shown by the experiment in Figure 6B, we have assayed for the ability of E1A to block the formation of $E 2 F_{c}$ rather than to dissociate the already formed complex. In this experiment, E1A protein was added at the same time as E2F$\mathrm{BF}$ is added to the free $\mathrm{E} 2 \mathrm{~F}$ rather than after formation of the complex. After incubation, E2F formation was measured by native gel electrophoresis, as shown in Figure 6B. Similar to the dissociation assay, we find that the wild-type E1A protein is capable of preventing the formation of the complex. Moreover, it is also clear that this activity requires $\mathrm{CR} 1$, as did the dissociation activity seen in Figure 6A. However, in contrast to the assays 


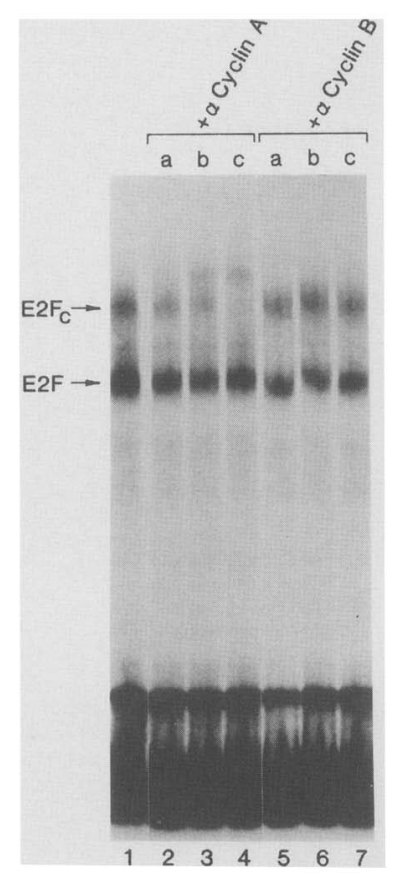

Figure 5. Reconstituted $E 2 \mathrm{~F}_{\mathrm{c}}$ contains the cyclin-A polypeptide. E2F-BF was incubated with E2F to allow formation of E2F Dilutions of the cyclin-A or cyclin-B antiserum were then added, incubation was continued, and E2F DNA binding was assayed by gel retardation. (Lanes a) $1: 256$ dilution of the antiserum; (lanes b) $1: 64$ dilution; (lanes c) 1:16 dilution. The sample in the first lane received no antiserum.

of dissociation of the already formed complex, CR2 is not necessary to block the formation of the complex. That is, several mutants in CR2, such as the 928 and the 961 point mutations (Fig. 6B, lanes 13 and 14 ), are able to prevent the formation of the complex, whereas each of these mutants was defective in bringing about the dissociation of the already formed complex. We therefore conclude from these assays that sequences in CR1 of the ElA protein are necessary both for the dissociation of $E 2 F_{c}$ and for the inhibition of formation of the complex. In contrast, CR2 is only necessary for the dissociation event.

\section{Detection and isolation of a factor that inhibits E2F DNA binding}

During the purification of E2F-BF, we also noticed an activity that appeared to reduce or eliminate E2F-binding activity. Because the formation of $E 2 F_{c}$ naturally results in the loss of free E2F, the presence of a separate inhibiting activity was not evident in the assays of crude extracts. However, as the purification of the binding protein proceeded, it became apparent that there must be an additional activity. For instance, there was an inhibition of E2F-binding activity in fractions of a DEAE-chromatography step that were separate from those containing E2F-BF (data not shown). That this was indeed a distinct activity, which abolishes the ability of E2F to bind to
DNA, was established by further purification. Chromatography of the DEAE pool on a hydroxyapatite column and sedimentation in a glycerol gradient revealed a distinct peak of activity that sedimented consistent with a molecular mass of $\sim 220 \mathrm{kD}$ (Fig. 7A). We have termed this activity E2F-I for an activity that inhibits the binding of E2F to DNA.

Although it is possible that the inhibition was the result of an irreversible inactivation of the protein, for instance, a protease that resulted in the destruction of E2F, several observations suggest that this was not the case but, rather, involved the formation of an inactive complex. First, whereas E2F-I inhibited E2F DNA binding, this activity had no effect on the binding of the E4F transcription factor (Fig. 7B). Thus, there is specificity to the inhibition. Second, E2F-binding activity can be recovered after the inhibition is complete by treatment with deoxycholate (data not shown). Third, addition of wildtype E1A protein can regenerate E2F-binding activity following the incubation with the E2F-I activity as shown in Figure 8A. Thus, E2F-binding activity was not destroyed by incubation with E2F-I but, rather, was masked in some manner. An analysis of the E1A mutants for the ability to reverse the inhibition by E2F-I revealed the same sequence requirements as those for the dissociation of E2F $F_{c}$ formed with E2F-BF (Fig. 8A). That is, a mutant in the amino terminus retained activity as did a mutant in the region between CR1 and CR2. In contrast, the two CR1 deletion mutants, as well as a domain 2 mutant, were inactive. An assay for the ability of E1A to block the inhibitory action of E2F-I rather than to reverse it is shown in Figure 8B. Similar to the results shown in Figure 6B, CR1 was required but CR2 was not required. It thus appears that two activities that alter the binding of the E2F transcription factor-in one case through the formation of a larger complex and in the other case through the inhibition of DNA binding - are affected by $\mathrm{E} 1 \mathrm{~A}$ in a similar manner.

\section{Discussion}

We believe that the experiments we describe here are of significance in three ways: (1) They establish a biochemical mechanism for the activation of transcription by a viral regulatory protein, the 243 -amino-acid product of the E1A 12S RNA; (2) they define the molecular requirements for this event and describe the interplay between the viral protein and the cellular components; and (3) they demonstrate that the transcriptional activation involves ElA sequences that are also important for oncogenesis.

\section{A biochemical mechanism for transcription activation mediated by the $12 S$ E1A product}

A series of experiments have clearly defined the role of the 289-amino-acid product of the adenovirus 13S E1A mRNA in transcriptional activation (Berk et al. 1979; Jones and Shenk 1979; Nevins 1981; Ricciardi et al. 1981). This activity is dependent on sequence in CR3, 

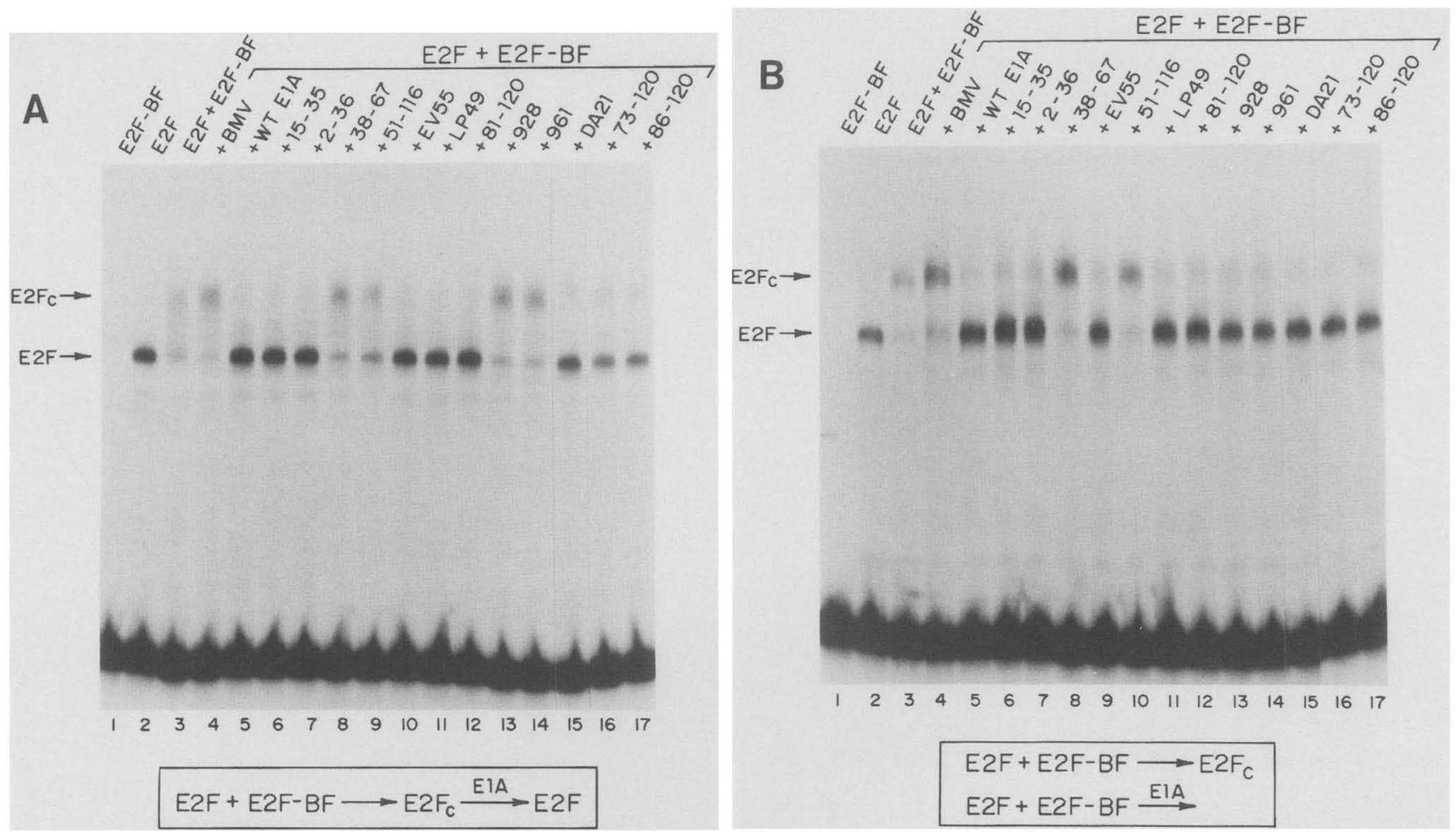

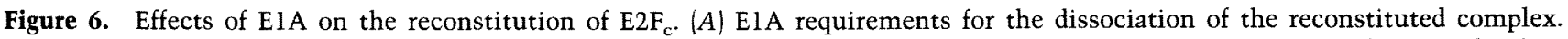
Glycerol gradient-purified E2F-BF $(2 \mu \mathrm{l})$ was incubated alone or with free E2F for 20 min at room temperature in the DNA-binding reaction mix. The reconstituted complex was then incubated further for $20 \mathrm{~min}$ with $1 \mu 1$ of a $1: 5$ dilution of reticulocyte lysates programmed with the various mutant E1A mRNAs or BMV RNA. The DNA-protein complexes were then analyzed by gel electrophoresis. The pattern of $\mathrm{E}_{2} \mathrm{~F}_{\mathrm{c}}$ formed by E2F alone is also shown (lane 2). (B) E1A requirements for the inhibition of complex formation. The ingredients and protocol of this experiment are the same as described in $A$, except that the reticulocyte lysates were added before the addition of E2F-BF to the reaction mixture and the incubation was carried out in one step for 20 min at room temperature.

and several mechanisms have been attributed to this function (Bagchi et al. 1989; Lillie and Green 1989; Raychaudhuri et al. 1989; Liu and Green 1990). It is also true that the 243-amino-acid product of the E1A 12 S mRNA can function as a trans-activator, although this phenomenon has received less attention. In part, this is likely due to a variability of results. In particular, some experiments have indicated that the $12 \mathrm{~S}$ product does not trans-activate at all (Lillie et al. 1986, 1987; Moran et al. $1986 a, b)$, whereas others have described activity that is reduced compared to that of the $13 \mathrm{~S}$ product and possibly was only significant for certain cellular targets (Winberg and Shenk 1984; Simon et al. 1987; Zerler et al. 1987). Other studies demonstrated that the $12 \mathrm{~S}$ ElA activation was nearly as strong as the $13 \mathrm{~S}$ activation and that early viral genes, including the E2 gene, could be the targets of activation (Leff et al. 1984; Ferguson et al. 1985). Our recent experiments have provided a rational explanation for these variable results and, more importantly, have provided a biochemical mechanism for the activation process. Specifically, we have shown that the cellular transcription factor E2F can be found in complexes with cellular factors (Bagchi et al. 1990). We have also shown that such complexes are inhibitory for transcription of the early E2 gene that normally makes use of the E2F factor. However, through the action of the E1A protein, independent of CR3, there is a dissociation of these complexes, relieving the inhibitory effect. This inhibitory effect can be explained most easily in light of the results presented here identifying a factor that blocks E2F binding. Clearly, the E1A-mediated dissociation of this complex would stimulate $\mathrm{E} 2$ transcription. It is also possible, however, that the complex containing E2F that is still capable of binding DNA is also inhibitory for E2 transcription.

In a lytic viral infection, the release of E2F from these complexes allows the $19-\mathrm{kD}$ product of the early $\mathrm{E} 4$ gene to interact with E2F and facilitate the formation of a stable complex on the E2 promoter (Hardy et al. 1989; Huang and Hearing 1989; Raychaudhuri et al. 1990), a process that further enhances E2 transcription (Babiss 1989; Reichel et al. 1989; Neill et al. 1990). We believe that the variation from experiment to experiment in many past reports is probably a function of the target promoter. For instance, we have found that the $12 \mathrm{~S}$ E1A product cannot trans-activate the $\mathrm{E} 3$ or $\mathrm{E} 4$ promoters (V. Kraus and J. Nevins, unpubl.). It is also clear that the cell type used for the trans-activation assays influences the results. That is, it is apparent that the 12S ElA-mediated stimulation will only be observed in circumstances 
Raychaudhuri et al.
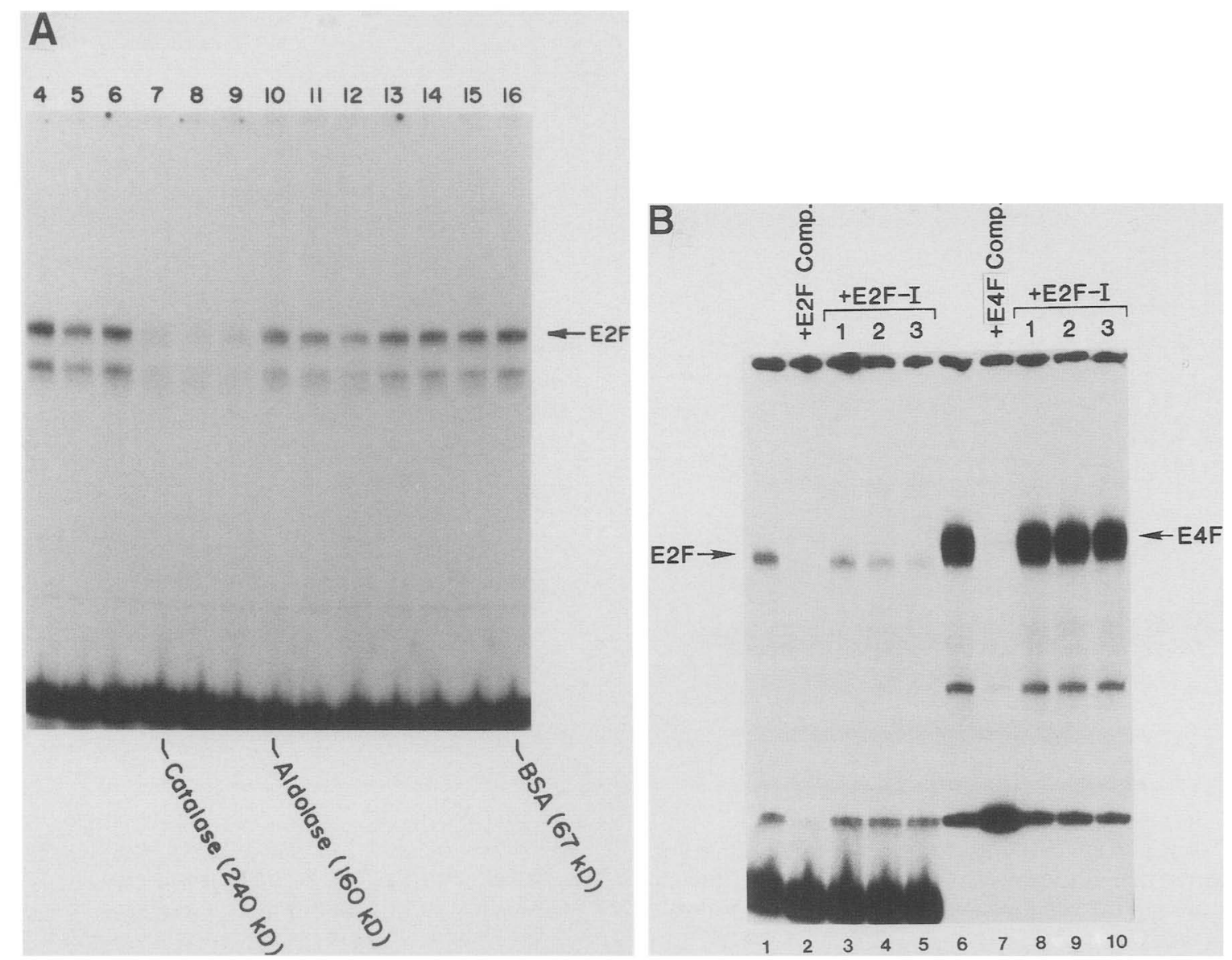

Figure 7. Identification of E2F-I activity. $|A|$ DEAE fractions containing an activity that inhibited E2F DNA binding were pooled and further purified by hydroxyapatite chromatography. Peak fractions from the hydroxyapatite column were pooled and sedimented in a 15-32\% glycerol gradient. Each fraction was assayed for activity that could inhibit E2F binding to DNA. Markers were run in a parallel gradient. The band running below the indicated E2F band is a degradation product of E2F. $(B)$ Specificity of E2F-I. Increasing amounts of glycerol gradient-purified E2F-I were incubated with E2F (lanes 3-5) or with E4F (lanes 8-10). Assays of E2F alone or E4F alone are shown in lanes 1 and 6, respectively. Specificity of binding was demonstrated by specific competition (lanes 2 and 7 ).

where E2F is complexed to other factors. This situation may be the normal one, but it is not found in HeLa cells, a cell system utilized for many studies of ElA transactivation. Although not proved, it seems a likely possibility that this property of HeLa cells is due to the expression of the human papillomavirus (HPV) E7 gene in this cell line. The $\mathrm{E} 7$ product trans-activates the $\mathrm{E} 2$ promoter (Phelps et al. 1988), the E7 protein shares sequence with E1A corresponding to these regions we have shown to be important for E2F dissociation, and recent experiments have now demonstrated that the $\mathrm{E} 7$ protein possesses an activity that disrupts E2F complexes (W. Phelps, S. Bagchi, P. Raychaudhuri, K. Munger, P. Howley, and J. Nevins, in prep.).

The results presented in this study now clearly demonstrate a requirement for E1A sequences in CR 1 and CR2 in altering the interactions of cellular factors with the E2F transcription factor. Moreover, through the partial purification of a factor (E2F-BF) that can regenerate $E 2 F_{c}$, we have been able to partially dissect the require- ments of E1A for altering the E2F interactions. As presented in Figure 6, sequences within CR1 are required both to dissociate E2F complexes and to block the formation of $\mathrm{E}_{2} \mathrm{~F}_{\mathrm{c}}$ upon addition of E2F-BF. In contrast, sequences within $\mathrm{CR} 2$ are only required for the dissociation of $\mathrm{E}_{\mathrm{c}} \mathrm{F}_{\mathrm{c}}$ and are not required for blocking the formation of the complex. Because an E1A protein containing a functional CRl can block the formation of the complex, and this does not require the presence of CR2, we suggest that sequences upstream of the CR2 portion of the E1A protein, dependent on CR1, are sufficient to recognize and bind to E2F-BF in such a way that the interaction with E2F is blocked. In simplest terms, it appears that a region of the E1A protein involving the $\mathrm{CR} 1$ sequence can compete with E2F for binding to E2F$B F$. If sequences upstream of CR2, dependent on CR1, interact with a domain of the binding factor that recognizes E2F, it is not surprising that these sequences alone do not dissociate $E 2 F_{c}$, as this site would already be bound by E2F. 


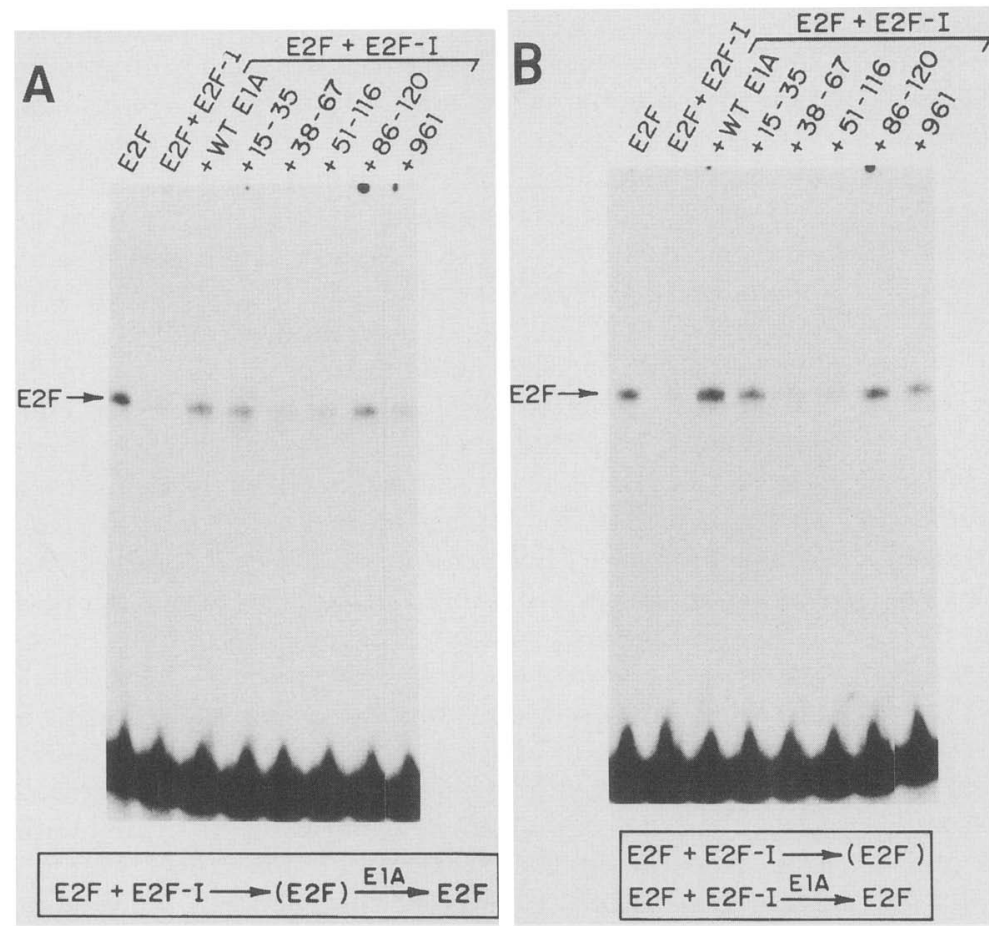

Figure 8. Effects of E1A on the inhibition of E2F DNA binding by E2F-I. (A) Reversal of E2F-I inhibition. E2F was incubated with glycerol gradient-purified E2F-I in the DNA-binding buffer for $20 \mathrm{~min}$ at room temperature. After the incubation, $1 \mu \mathrm{l}$ of a $1: 5$ dilution of reticulocyte lysates programmed with the indicated E1A mutant mRNAs was added and the incubation was continued for another $20 \mathrm{~min}$. The reaction mixes were analyzed by native gel electrophoresis. The patterns of complex formed in the absence of reticulocyte lysates by E2F alone (lane 1) and that in the presence of E2F-I (E2F + E2F-I; lane 2) are shown. (B) E1A requirements for preventing E2F-I-mediated inhibition. The assay was conducted in the same way as described in $A$, except that addition of the E1A proteins preceded that of E2F-I and the incubation was carried out in a single step for $20 \mathrm{~min}$ at room temperature.
How, then, might CR2 contribute to the dissociation? In considering the dissociation process, we suggest that E1A may simply alter the normal equilibrium of the dissociation-association event. That is, depending on the binding constants, the E2F/E2F-BF complex will be in equilibrium with the dissociated components. If this dissociation is slow, and the affinity of the E1A protein (in the absence of CR2) for the E2F-BF protein is low, then only very high concentrations of the protein would alter the equilibrium. If, however, the presence of an intact CR2 domain either increased the affinity of these sequences for E2F-BF or brought the E1A protein to the complex by virtue of recognition of a second site on E2F$\mathrm{BF}$, the effective concentration of the protein would be greatly increased such that any dissociated E2F-BF would be prevented from reassociating with E2F; thus, the equilibrium between $\mathrm{E} 2 \mathrm{~F}_{\mathrm{c}}$ and the component parts would be shifted toward dissociation.

Perhaps it is also useful to consider the issue of E1Amediated repression in light of the role of E1A in dissociating transcription factor complexes, because various experiments have suggested a link between ElA repression and interaction with cell proteins. For instance, recent results have shown that interaction of E1A with a $300-\mathrm{kD}$ polypeptide requires sequence at the extreme amino terminus of the E1A protein (Egan et al. 1988; Whyte et al. 1989) and correlates with the ability of E1A to repress transcription driven by the insulin enhancer (Stein et al. 1990). These events are independent of sequence in CR2 and, thus, independent of interaction with proteins such as the $\mathrm{Rb}$ protein, as well as the E2F interactions we describe here. Nevertheless, other studies have provided evidence for a CR2 requirement in transcription repression (Lillie et al. 1986). Possibly, the requirement for the amino terminus in one case or CR2 in another case is a function of the enhancer target, reflecting the specificity of protein interactions. That is, one complex may be important for the insulin enhancer, but another is important for the SV40 enhancer. With respect to a mechanism for repression, we believe that there is a strong analogy to the events we describe here for E2F. Our experiments suggest that E2F is complexed with a factor that inhibits its activity and the release of E2F thus stimulates transcription. The precise same mechanism could achieve the opposite result, a repression, if the target for dissociation was a positive-acting complex for an enhancer. That is, an E1A-mediated dissociation would leave the DNA-binding protein void of a transcriptional activating cofactor. This would then lead to a loss of transcription and, consequently, a repression.

\section{Role of transcription factor dissociation in oncogenesis}

A series of experiments have defined the sequence requirements for the oncogenic transformation activity of the E1A protein. From these studies it is clear that CR3 of E1A is not required or only exerts a subtle change in the phenotype of the transformed cell; in general, the 12S E1A gene product is fully capable of transformation. Within the $12 \mathrm{~S}$ product, sequences at the amino terminus, sequences within CR1, and sequences within CR2 have been shown to be important for transformation $/ \mathrm{Ha}$ ley et al. 1984; Lillie et al. 1986; Moran et al. 1986b; Schneider et al. 1987; Zerler et al. 1987; Smith and Ziff 1988; Subramanian et al. 1988; Whyte et al. 1988; Jelsma et al. 1989). A summary of all of these experiments sug- 
gests that residues $1-25,36-77$, and $121-139$ are required for full transforming activity (Fig. 91. Our results have shown that $\mathrm{CR} 1$ and $\mathrm{CR} 2$ sequences are required for dissociation of E2F complexes; thus, those sequences important for E2F dissociation are also necessary for oncogenic activity. Moreover, the two point mutants in CR1 (EV55 and LP49) that were wild type for E2F dissociation are also wild type for transformation (E. Moran, unpubl.). This E2F-directed activity cannot be sufficient for transformation because the amino-terminal sequences were dispensable for $\mathrm{E}_{2} \mathrm{~F}_{\mathrm{c}}$ dissociation but clearly are required for transformation. We presume that transformation mediated by the $12 \mathrm{~S}$ El A product must be the result of targeting more than one cellular component. The immunoprecipitation assays for cellular proteins associated with $\mathrm{ElA}$ indicate that the interaction of a $300-\mathrm{kD}$ protein with $\mathrm{E} 1 \mathrm{~A}$ is dependent on amino-terminal sequences but not CR2 sequence, whereas other proteins such as p105 Rb do not require the amino terminus but do require CR2 (Egan et al. 1988; Whyte et al. 1989; Stein et al. 1990). Interestingly, CR1 appears to be required for stable interactions with most of the associated cellular proteins, including $\mathrm{Rb}$ and the $300 \mathrm{~K}$ protein.

A careful comparison of the transforming activity of certain mutants to the E2F-dissociating activity does reveal some inconsistencies. For instance, the activity of the $\Delta 51-116$ deletion is only mildly reduced in some transformation assays (Stein et al. 1990), yet it is clearly impaired in E2F dissociation and trans-activation. Nevertheless, other assays have shown that a deletion of E1A sequence between residue 62 and 85 , a region totally deleted by the 51-116 mutant, is defective for transformation (Whyte et al. 1989). In addition, the 961 mutant is not completely defective for transformation (Moran et al. 1986a, b), and in other assays a deletion to this point has exhibited some transforming activity (Whyte et al.

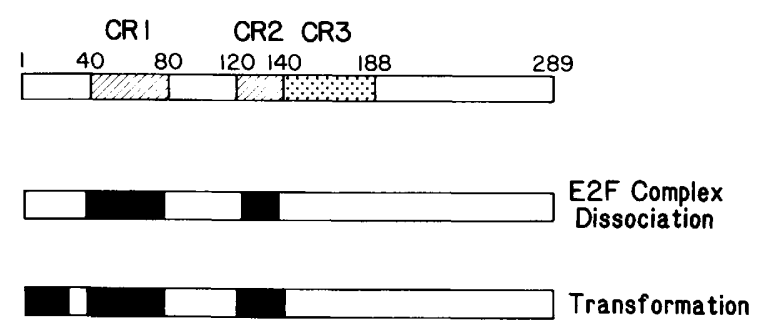

Figure 9. Comparison of E1A sequences involved in E2F $F_{c}$ dissociation and oncogenic transformation. (Top) A schematic of the 289-amino-acid product of the 13S RNA, containing the CR1 and CR2 domains, as well as CR3, which is unique to the 13S E1A product. The segments of ElA that are required for E2 $F_{c}$ dissociation are depicted. These regions extend from residue 38 to 73 and from residue 124 to 135 , on the basis of the assays presented in this paper. Definition of the segments required for ElA-dependent transformation, in conjunction with the activated ras oncogene, derives from various previous studies (Lillie et al. 1986; Moran et al. 1986b; Zerler et al. 1986; Whyte et al. 1988, 1989; Jelsma et al. 1989; Stein et al. 1990) and include residues 1-26, 35-77, and 121-139.
1988). We interpret these variable results to simply reflect assay-dependent differences in transforming function that, depending on contributions from the host cell, influence the extent to which a particular region is required in generating the final phenotype.

If the E2F-dissociating activity of E1A does coincide with oncogenic activity of E1A, how might this specific biochemical activity have an impact on the regulation of cell growth? E2F-binding sites have been found in a number of cellular genes, including c-myc, N-myc, c-myb, DHFR, and epidermal growth factor (EGF) receptor (Hiebert et al. 1989; Mudryj et al. 1990); and at least for the c-myc and DHFR genes, the E2F sites have been shown to be important for transcriptional activity (Blake and Azizkhan 1989; Thalmeier et al. 1989). Recent experiments have shown that there are changes in the nature of the E2F-containing complexes that appear to reflect transitions between stages of the cell cycle (Mudryi et al. 1991). In particular, one complex accumulates during $S$ phase and then disappears at the end of $S$ phase. This complex contains the cyclin-A protein and thus appears to be the same as the complex that is reconstituted with E2F-BF. Although the precise functional role of these interactions is not yet clear, the tight control evident during the cell proliferative cycle and the observation that various genes regulated during cell proliferation utilize E2F suggest a functional significance. The ability of E1A to alter these interactions, dependent on E1A sequence, which is also important for oncogenic transformation, is consistent with a role for this E1A activity in disrupting cell proliferation control.

\section{Materials and methods}

Preparation of E2F

$E 2 F_{c}$ was isolated from $L$-cell extracts as was described previously (Bagchi et al. 1990). Extracts of undifferentiated F9 teratocarcinoma cells were used as the source of free E2F in the assays of E2F-BF.

\section{Assay of E4F}

The isolation of $\mathrm{E} 4 \mathrm{~F}$ and the conditions for assay of binding have been described previously (Raychaudhuri et al. 1987; Rooney et al. 1990).

\section{E1A mutants}

Construction of the E1A mutant plasmids designated d186-120 (referred to previously as ElA-NCdl), pm928, and pm961, has been described previously (Moran et al. 1986b). The plasmids designated 15-35, 2-36, 51-116, 73-120, 76-120, and 81-120 in this study are $12 \mathrm{~S}$ cDNA versions of genomic plasmids also described previously (Stein et al. 1990). The single-residue substitution mutants, p12S.DA21 (changing Asp21 to Ala), p12S.LP49 (changing Leu49 to Pro), and p12S.EV55 (changing Glu55 to Val), were constructed by standard oligonucleotidedirected mutagenesis techniques. A restriction fragment containing the point mutation was subcloned into a 12S.WT parent plasmid, and the presence of the single-residue substitutions was verified by dideoxy sequencing through the entire restriction fragment. The plasmid designated p12S.38-67 was con- 
structed by removing the intervening fragment between the $X$ hoI linkers in the linker-insertion mutants pSVXL132 (deleting residues 38-44) and pSVXL124 (deleting residues 64-67) (Velcich and Ziff 1988; obtained from Ed Ziff and Roland Stein). An appropriate restriction fragment of the resulting plasmid was subcloned into a 12S.WT background. The presence of the mutation was verified by dideoxy sequencing of the subcloned fragment. As a result of the linker insertion, this plasmid encodes a deletion of residues 38-67 with an insertion of three residues-Ser-Ser-Arg-between residues 37 and 68 .

\section{In vitro translation of $E 1 A$ proteins}

EcoRI-PstI DNA fragments of cDNAs encoding wild-type or mutant sequences of the $12 \mathrm{~S}$ gene products of ElA were cloned at the EcoRI-PstI sites of pGEM-4. The pGEM plasmids containing E1A sequences were linearized with PstI, and capped RNAs were made as described previously (Bagchi et al. 1990). RNAs were translated in vitro using the reticulocyte lysate translation kit from Promega Biotechnology. $\left[{ }^{35}\right.$ S $\mid$ Methioninelabeled full-length translation products were assayed by SDSpolyacrylamide gel electrophoresis and autoradiography.

\section{Transfection assays}

Transfection assays were performed as described previously using DEAE-dextran procedures (Cullen 1987). Dishes (60 mm) of mouse $L$ cells at $70 \%$ confluency were transfected with a total of $3 \mu \mathrm{g}$ of DNA. pA10CAT-E2F plasmid $(1 \mu \mathrm{g})$ and $1 \mu \mathrm{g}$ of E1A or mutant E1A-expressing plasmids, along with pGEM-4 DNA, were used in these experiments. Cells were harvested $48 \mathrm{hr}$ post-transfection, and CAT assays were performed as described previously (Simon et al. 1988). The pA10CAT-E2F plasmid has been described (Yee et al. 1989) and consists of the two E2F sites from the E2 promoter cloned upstream of the early SV40 promoter in the plasmid pA10CAT2.

\section{Purification of E2F-BF}

The heparin-agarose $0.25 \mathrm{M}$ fraction, obtained by fractionating whole-cell extracts prepared from 24 liters of $\mathrm{L}$ cells, was dialyzed against 3 liters of buffer A containing $50 \mathrm{~mm} \mathrm{KCl}$ for $4 \mathrm{hr}$. Buffer A contained $20 \mathrm{~mm}$ Tris- $\mathrm{HCl}(\mathrm{pH} 7.5), 0.5 \mathrm{~mm}$ DTT, 0.2 $\mathrm{mM}$ PMSF, and $10 \%$ (vol/vol) glycerol. The dialyzed material was then applied to a DEAE-Sepharose column (100 ml for 400 mg of protein), which was equilibrated previously with buffer $A$ containing $50 \mathrm{~mm} \mathrm{KCl}$. The column was washed successively with $300 \mathrm{ml}$ of buffer A plus $50 \mathrm{mM} \mathrm{KCl}$ and $300 \mathrm{ml}$ of buffer A plus $100 \mathrm{mM} \mathrm{KCl}$ and then eluted with a linear $\mathrm{KCl}$ gradient of $800 \mathrm{ml}$, ranging from 100 to $400 \mathrm{mM} \mathrm{KCl}$ concentration. A sample of $3 \mu \mathrm{l}$ of the alternate column fractions $(10 \mathrm{ml})$ was assayed for E2F-BF.

The DEAE column fractions between 30 and 35 were pooled (32 $\mathrm{mg}$ of total protein), adjusted to $10 \mathrm{~mm}$ potassium phosphate (pH 7.0), and applied to a hydroxyapatite column $(8 \mathrm{ml})$. The column was first washed with $80 \mathrm{~mm}$ potassium phosphate $/ \mathrm{pH}$ 7.0 containing buffer $B$ and then eluted with a 10 bed volume gradient from 80 to $400 \mathrm{~mm}$ potassium phosphate containing buffer $\mathrm{B}$. Buffer $\mathrm{B}$ contained the indicated amount of potassium phosphate ( $\mathrm{pH} 7.0)$, along with $0.2 \mathrm{mM} \mathrm{DTT}, 0.2 \mathrm{mM} \mathrm{PMSF}$, and $10 \%$ (vol/vol) glycerol. One-milliliter fractions were collected, and $1 \mu \mathrm{l}$ of the indicated fractions was assayed for E2F-BF.

The hydroxyapatite-purified material was concentrated using a Centricon apparatus. An aliquot $(100 \mu \mathrm{l}, \sim 0.5 \mathrm{mg}$ of protein $\}$ was applied to a $4.2-\mathrm{ml}$ glycerol gradient $[12-35 \%(\mathrm{vol} / \mathrm{vol})]$ and centrifuged using a SW60 rotor at $50,000 \mathrm{rpm}$ for $18 \mathrm{hr}$. The gradient tube was punctured at the bottom, and $0.2-\mathrm{ml}$ fractions were collected. A sample of $2 \mu \mathrm{l}$ from each fraction was assayed for E2F-BF. A gradient containing molecular mass marker proteins (catalase, aldolase, and bovine serum albumin, $100 \mu \mathrm{g}$ each/ was centrifuged in parallel. The marker proteins were assayed by SDS-gel electrophoresis.

\section{Antiserum}

The cyclin-A and cyclin-B antisera were generous gifts of $\mathrm{J}$. Pines and T. Hunter (Salk Institute) (Pines and Hunter 1989, 1990).

\section{Acknowledgments}

We thank Mary Corrigan Carter and Lynne Dengler for their excellent technical assistance. E.M. is the recipient of an American Cancer Society Junior Faculty Research Award (JFRA-206). This work was supported by grants from the National Institutes of Health to E.M. (CA-46436) and to J.N. (GM-26725).

The publication costs of this article were defrayed in part by payment of page charges. This article must therefore be hereby marked "advertisement" in accordance with 18 USC section 1734 solely to indicate this fact.

\section{References}

Babiss, L.E. 1989. The cellular transcription factor E2F requires viral E1A and E4 gene products for increased DNA-binding activity and functions to stimulate adenovirus E2A gene expression. J. Virol. 63: 2709-2717.

Bagchi, S., P. Raychaudhuri, and J.R. Nevins. 1989. Phosphorylation-dependent activation of the adenovirus-inducible E2F transcription factor in a cell-free system. Proc. Natl. Acad. Sci. 86: 4352-4356.

- 1990. Adenovirus E1A proteins can dissociate cellular complexes containing the E2F transcription factor: A novel mechanism for E1A trans-activation. Cell 62: 659-669.

Berk, A.J., F. Lee, T. Harrison, J. Williams, and P.A. Sharp. 1979. Pre-early adenovirus 5 gene product regulates synthesis of early viral messenger RNAs. Cell 17: 935-944.

Blake, M.C. and J.C. Azizkhan. 1989. Transcription factor E2F is required for efficient expression of the hamster dihydrofolate reductase gene in vitro and in vivo. Mol. Cell. Biol. 9: 4994 5002.

Cullen, B.R. 1987. Use of eukaryotic expression technology in the functional analysis of cloned genes. Methods Enzymol. 152: 684-704.

Egan, C., T.N. Jelsma, J.A. Howe, S.T. Bayley, B. Ferguson, and P.E. Branton. 1988. Mapping of cellular protein-binding sites on the products of early-region $1 \mathrm{~A}$ of human adenovirus type 5. Mol. Cell. Biol. 8: 3955-3959.

Ferguson, B., B. Krippl, O. Andrisani, N. Jones, H. Westphal, and M. Rosenberg. 1985. E1A 13S and 12S mRNA products made in Escherichia coli both function as nucleus-localized transcription activators but do not directly bind DNA. Mol. Cell. Biol. 5: 2653-2661.

Gerster, T. and R.G. Roeder. 1988. A herpesvirus trans-activating protein interacts with transcription factor OTF- 1 and other cellular proteins. Proc. Natl. Acad. Sci. 85: 6347-6351.

Haley, K.P., J. Overhauser, L.E. Babiss, H.S. Ginsberg, and N.C. Jones. 1984. Transformation properties of type 5 adenovirus mutants that differentially express the ElA gene products. Proc. Natl. Acad. Sci. 81: 5734-5738.

Hardy, S., D.A. Engel, and T. Shenk. 1989. An adenovirus early 
region 4 gene product is required for induction of the infection-specific form of cellular E2F activity. Genes \& Dev. 3: $1062-1074$.

Hiebert, S.W., M. Lipp, and J.R. Nevins. 1989. E1A-dependent trans-activation of the human MYC promoter is mediated by the E2F factor. Proc. Nat1. Acad. Sci. 86: 3594-3598.

Huang, M.M. and P. Hearing. 1989. Jun. Adenovirus early region 4 encodes two gene products with redundant effects in lytic infection. J. Virol. 63: 2605-2615.

Jelsma, T.N., J.A. Howe, J.S. Mymryk, C.M. Evelegh, N.F.A. Cunnif, and S.T. Bayley. 1989. Sequences in E1A proteins of human adenovirus 5 required for cell transformation, repression of a transcriptional enhancer, and induction of proliferating cell nuclear antigen. Virology 170: 120-130.

Jones, N. and T. Shenk. 1979. An adenovirus type 5 early gene function regulates expression of other early viral genes. Proc. Natl. Acad. Sci. 76: 3665-3669.

Kimelman, D., J.S. Miller, D. Porter, and B.E. Roberts. 1985. E1a regions of the human adenovirus and the highly oncogenic simian adenovirus 7 are closely related. J. Virol. 53: 399-409.

Leff, T., R. Elkaim, C.R. Goding, P. Jalinot, C.P. Sassone, M. Perricaudet, C. Kedinger, and P. Chambon. 1984. Individual products of the adenovirus $12 \mathrm{~S}$ and 13 S EIa mRNAs stimulate viral EIIa and EIII expression at the transcriptional level. Proc. Natl. Acad. Sci. 81: 4381-4385.

Lillie, J.W. and M.R. Green. 1989. Transcription activation by the adenovirus Ela protein. Nature 338: $39-44$.

Lillie, J.W., M. Green, and M.R. Green. 1986. An adenovirus E1a protein region required for transformation and transcriptional repression. Cell 46: 1043-1051.

Lillie, J.W., P.W. Lowenstein, M.R. Green, and M. Green. 1987. Functional domains of adenovirus type $5 \mathrm{Ela}$ proteins. Cell 50: 1091-1100.

Lipp, M., R. Schilling, S. Wiest, G. Laux, and G.W. Bornkamm. 1987. Target sequences for cis-acting regulation within the dual promoter of the human c-myc-gene. Mol. Cell. Biol. 7: 1393-1400.

Liu, F. and M.R. Green. 1990. A specific member of the ATF transcription factor family can mediate transcription activation by the adenovirus Ela protein. Cell 61: 1217-1224.

Marton, M.J., S.B. Baim, D.A. Ornelles, and T. Shenk. 1990. The adenovirus E4 17-kilodalton protein complexes with the cellular transcription factor E2F, altering its DNA-binding properties and stimulating ElA-independent accumulation of E2 mRNA. I. Virol. 64: 2345-2359.

McKnight, J.L., T.M. Kristie, and B. Roizman. 1987. Binding of the virion protein mediating alpha gene induction in herpes simplex virus 1 -infected cells to its cis site requires cellular proteins. Proc. Natl. Acad. Sci. 84: 7061-7065.

Mitchell, P.J. and R. Tjian. 1989. Transcriptional regulation in mammalian cells by sequence-specific DNA binding proteins. Science 245: 371-378.

Moran, E., T. Grodzicker, R.J. Roberts, M.B. Mathews, and B. Zerler. 1986a. Lytic and transforming functions of individual proteins of the adenovirus ElA gene. I. Virol. 57: 765-775.

Moran, E., B. Zerler, T.M. Harrison, and M.B. Mathews. 1986b. Identification of separate domains in the adenovirus E1A gene for immortalization activity and the activation of virus early genes. Mol. Cell. Biol. 6: 3470-3480.

Mudryi, M., S.W. Hiebert, and J.R. Nevins. 1990. A role for the adenovirus inducible E2F transcription factor in a proliferation-dependent signal transduction pathway. EMBO $I$. 7: 2179-2184.

Mudryj, M., S.H. Devoto, S.W. Hiebert, T. Hunter, J. Pines, and J.R. Nevins. 1991. Cell cycle regulation of the E2F transcription factor involves an interaction with cyclin A. Cell (in press).

Neill, S.D., C. Hemstrom, A. Virtanen, and J.R. Nevins. 1990. An adenovirus E4 gene product trans-activates E2 transcription and stimulates stable E2F binding through a direct association with E2F. Proc. Natl. Acad. Sci. 87: 2008-2012.

Nevins, J.R. 1981. Mechanism of activation of early viral transcription by the adenovirus ElA gene product. Cell 26: 213220.

O'Hare, P. and C.R. Goding. 1988. Herpes simplex virus regulatory element and the immunoglobulin octamer domain bind a common factor and are both targets for virion transactivator. Cell 52: 435-445.

Phelps, W.C., C.L. Yee, K. Munger, and P.M. Howley. 1988. The human papillomavirus type $16 \mathrm{E} 7$ gene encodes transactivation and transformation function similar to those of adenovirus E1A. Cell 53: 539-547.

Pines, J. and T. Hunter. 1989. Isolation of a human cyclin cDNA: Evidence for cyclin mRNA and protein regulation in the cell cycle and for interaction with p34cdc2. Cell 58: 833846 .

- 1990. Human cyclin A is adenovirus E1A-associated protein p60 and behaves differently from cyclin B. Nature 346: $760-763$.

Preston, C.M., M.C. Frame, and M.E. Campbell. 1988. A complex formed between cell components and an HSV structural polypeptide binds to a viral immediate early gene regulatory DNA sequence. Cell 52: 425-434.

Pugh, B.F. and R. Tiian. 1990. Mechanism of transcriptional activation by Spl: Evidence for coactivators. Cell 61: 11871197.

Raychaudhuri, P., R. Rooney, and J.R. Nevins. 1987. Identification of an E1A-inducible cellular factor that interacts with regulatory sequences within the adenovirus E4 promoter. EMBO I. 6: 4073-4081.

Raychaudhuri, P., S. Bagchi, and J.R. Nevins. 1989. DNA-binding activity of the adenovirus-induced E4F transcription factor is regulated by phosphorylation. Genes \& Dev. 3: 620627.

Raychaudhuri, P., S. Bagchi, S. Neill, and J.R. Nevins. 1990. Activation of the E2F transcription factor in adenovirus infected cells involves an E1A-dependent stimulation of DNA binding activity and induction of cooperative binding mediated by an E4 gene product. J. Virol. 64: 2702-2710.

Reichel, R., S.D. Neill, I. Kovesdi, M. C. Simon, P. Raychaudhuri, and J.R. Nevins. 1989. The adenovirus E4 gene, in addition to the E1A gene, is important for trans-activation of E2 transcription and for E2F activation. I. Virol. 63: 36433650.

Ricciardi, R.P., R.L. Jones, C.L. Cepko, P.A. Sharp, and B.E. Roberts. 1981. Expression of early adenovirus genes requires a viral encoded acidic polypeptide. Proc. Natl. Acad. Sci. 78: 6121-6125.

Rooney, R.J., P. Raychaudhuri, and J.R. Nevins. 1990. E4F and ATF, two transcription factors that recognize the same site, can be distinguished both physically and functionally: A role for E4F in E1A trans-activation. Mol. Cell. Biol. 10: 51385149.

Schneider, J.F., F. Fisher, C.R. Goding, and N.C. Jones. 1987. Mutational analysis of the adenovirus Ela gene: The role of transcriptional regulation in transformation. EMBO $J$. 6: 2053-2060.

Shaw, P.E., H. Schroter, and A. Nordheim. 1989. The ability of a ternary complex to form over the serum response element correlates with serum inducibility of the human c-fos promoter. Cell 56: 563-572.

Simon, M.C., K. Kitchener, H.T. Kao, E. Hickey, L. Weber, R. 
Voellmy, N. Heintz, and J.R. Nevins. 1987. Selective induction of human heat shock gene transcription by the adenovirus E1A gene products, including the $12 \mathrm{~S}$ E1A product. Mol. Cell. Biol. 7: 2884-2890.

Simon, M.C., T.M. Fisch, B.J. Benecke, J.R. Nevins, and N. Heintz. 1988. Definition of multiple, functionally distinct TATA elements, one of which is a target in the hsp70 promoter for E1A regulation. Cell 52: 723-729.

Smith, D.H. and E.B. Ziff. 1988. The amino-terminal region of the adenovirus serotype $5 \mathrm{E} 1 \mathrm{~A}$ protein performs two separate functions when expressed in primary baby rat kidney cells. Mol. Cell. Biol. 8: 3882-3890.

Stein, R.L., M. Corrigan, P. Yaciuk, J. Whelan, and E. Moran. 1990. Analysis of E1A-mediated growth regulation functions: Binding of the 300-kilodalton cellular product correlates with E1A enhancer repression function and DNA synthesis-inducing activity. $J$. Virol. 64: 4421-4427.

Subramanian, R., M. Kapuswamy, R.J. Nasr, and G. Chinnadurai. 1988. An $\mathrm{N}$-terminal region of adenovirus E1A essential for cell transformation and induction of an epithelial growth factor. Oncogene 2: 105-112.

Thalmeier, K., H. Synovzik, R. Mertz, E.L. Winnacker, and M. Lipp. 1989. Nuclear factor E2F mediates basic transcription and trans-activatien by E1A of the human MYC promoter. Genes \& Dev. 3: 327-536.

Velchich, A. and E. Ziff. 1988. Adenovirus E1a ras cooperation activity is separate from its positive and negative transcription regulatory function. Mol. Cell. Biol. 8: 2177-2183.

Whyte, P., H.E. Ruley, and E. Harlow. 1988. Two regions of the adenovirus ElA gene are required for transformation. $J$. Virol. 62: 257-265.

Whyte, P., N.M. Williamson, and E. Harlow. 1989. Cellular targets for transformation by the adenovirus ElA proteins. Cell 56: 67-75.

Winberg, G. and T. Shenk. 1984. Dissection of overlapping functions within the adenovirus type $5 \mathrm{E} 1 \mathrm{~A}$ gene. EMBO J. 3: $1907-1912$.

Yee, A.S., P. Raychaudhuri, L. Jakoi, and J.R. Nevins. 1989. The adenovinus-inducible E2F factor stimulates transcription dependent on specific DNA binding. Mol. Cell. Biol. 9: 578585.

Zerler, B., B. Moran, K. Maruyama, J. Moomaw, T. Grodzicker, and H.E. Ruley. 1986. Adenovirus E1A coding sequences that enable ras and pmt oncogenes to transform cultured primary cells. Mol. Cell. Biol. 6: 887-899.

Zerler, B., R.J. Roberts, M.B. Mathews, and E. Moran. 1987. Different functional domains of the adenovirus E1A gene are involved in regulation of host cell cycle products. Mol. Cell. Biol. 7: 821-829. 


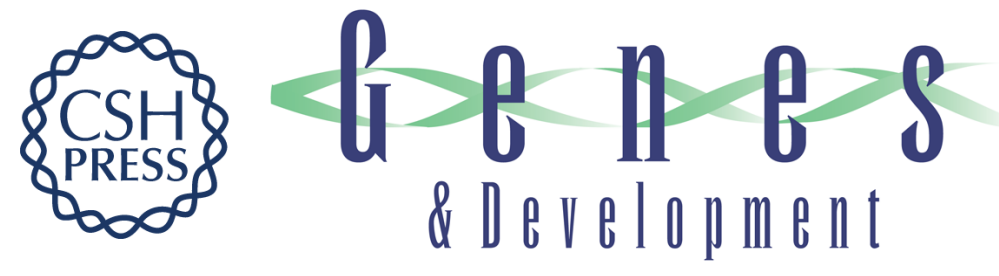

\section{Domains of the adenovirus E1A protein required for oncogenic activity are also required for dissociation of E2F transcription factor complexes.}

P Raychaudhuri, S Bagchi, S H Devoto, et al.

Genes Dev. 1991, 5:

Access the most recent version at doi:10.1101/gad.5.7.1200

References This article cites 57 articles, 33 of which can be accessed free at: http://genesdev.cshlp.org/content/5/7/1200.full.html\#ref-list-1

License

Email Alerting Service

Receive free email alerts when new articles cite this article - sign up in the box at the top right corner of the article or click here.

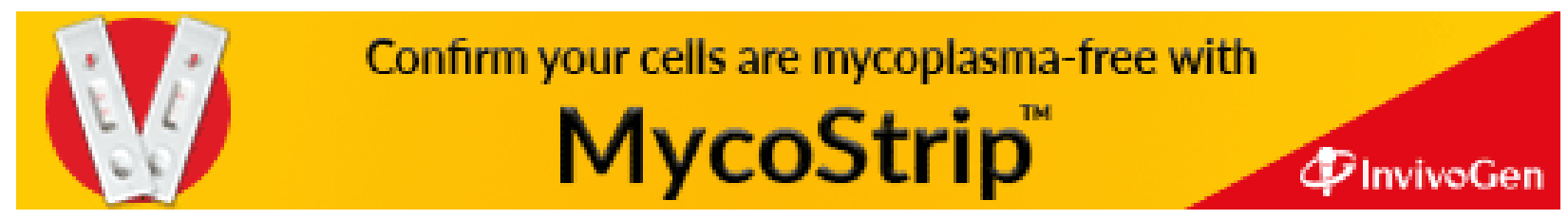

